\title{
Joaquim Cardozo e Pancetti, águas sem dono
}

\author{
Manoel Ricardo de Lima*
}

\begin{abstract}
Resumo:
Este trabalho parte da leitura que Joaquim Cardozo faz da imagem da água na pintura do marinheiro Pancetti como um elemento de "sentido quase místico da paisagem", uma espécie de "reconciliação com as paisagens do mundo", uma "solidariedade entre o ser e o agir, entre o ser e o continuar", tudo isto num movimento browniano de matizes. Cardozo chama esta imagem de águas sem dono. A questão deste trabalho é como ele re-elabora o seu conceito de forma-formante a partir da pintura de Pancetti.
\end{abstract}

\section{Palavras-chave:}

Forma-formante; paisagem; pintura; Joaquim Cardozo; Pancetti

Escolhi três imagens das pinturas de José Pancetti (1902-1958), ${ }^{1}$ o marinheiro pintor, para indicar as questões que Joaquim Cardozo (1893-1978) elabora para ver na sua pintura uma espécie de "sentido místico da paisagem" ou "uma reconciliação com as paisagens do mundo", a partir de um projeto singular como ato poético que se vincula a uma forma-formante, num movimento browniano² de

\footnotetext{
* Pós-doutorando CNPq/UFSC.

${ }^{1}$ Giuseppe Gianinni Pancetti nasceu na cidade de Campinas, em 1902, primeiro local escolhido por seus pais para viver no Brasil em 1891, ao chegarem de Toscana, na Itália. Logo se mudariam para a capital paulista. A família Pancetti firmou residência no bairro do Brás, local de duras memórias do garoto que desde cedo aportuguesou seu nome para José. A infância pobre e o alcoolismo do pai fizeram com que o então jovem Pancetti fosse, em 1913, para Itália.
}

${ }^{2}$ Em 1928, foi publicado, na revista científica inglesa Philosophical Magazine, um artigo com o simpático título "Uma breve descrição de observações microscópicas efetuadas nos meses de Junho, Julho e Agosto de 1827 sobre partículas contidas no pólen de plantas". Seu autor, o botânico Robert Brown, observou, através do microscópio, pequenos grãos de pólen de plantas leves que flutuavam dentro de água. O que ele achou surpreendente foi o movimento incessante desses grãos, deslocando-se de um lado para o outro em uma dança brusca. Inicialmente, Brown pensou que esse movimento fosse causado por algum minúsculo ser vivo morando dentro do grão. Mas não demorou para que observasse o mesmo tipo de comportamento em partículas de cinza e poeira flutuando em água. Um movimento associado ao movimento das moléculas da água. A explicação completa e rigorosa do movimento browniano foi dada por Albert Einstein, em 1905. Neste ano, Einstein publicou artigos que abalaram a Física. Um deles se intitulava "Sobre o movimento de partículas suspensas em um fluido em repouso". O caminho que uma partícula browniana percorre é irregular e imprevisível. Não dá para descrever rigorosamente essa trajetória, nem com palavras nem com uma expressão matemática. Aliás, os matemáticos sofrem um bocado com esse tipo de "curva", toda feita de ângulos e desvios súbitos. Tecnicamente, eles dizem que essa curva é "patológica", é uma curva contínua mas não tem derivada contínua em nenhum de seus pontos. Alguns anos depois do trabalho de Einstein, o matemático Nobert Wiener provou que a trajetória browniana tem comprimento infinito entre dois pontos quaisquer. $\mathrm{O}$ caminho traçado pela partícula é tão enrolado que se esperássemos um tempo infinitamente longo, ela percorreria todo o plano, sem deixar de passar por nenhum ponto. Tecnicamente se diz que, contrariando as aparências, o caminho percorrido pela partícula browniana não é uma linha (com dimensão), mas é uma superfície (com dimensão). A trajetória da partícula browniana é irregular, com um microscópio potente é possível ver que a curva é muito angulosa e irregular. http://www. searadaciencia.ufc.br/especiais/fisica/brown/brown.htm - consultado no dia 17.12.2009 
matizes e que Joaquim Cardozo chama de "águas sem dono". Assim, ele procura sair da leitura do figurativo de Pancetti para dar a este figurativo uma potência recuperada da atividade marítima, entre o mar, a água revolta e o remanso de areia.

A expressão forma-formante é um conceito que Joaquim Cardozo lança sobre um pensamento para a arte através da teoria do cálculo estrutural: o que pode se abrir por meio de um "esforço". Esforço é aquilo que vem num engendramento (e engendramento é aquilo que se concebe na imaginação, tem a ver com imaginar, engenhar, inventar) da teoria da deformação, porque no cálculo estrutural tudo é feito para que não se deforme nem deforme o "real" daquilo que constrói; para ele isto é um "estágio da experimentação em que o corpo se deformando começa a deformar, por sua vez, o corpo deformador". Daí, deste procedimento chamado de esforço ele retira a sua idéia de "forma formante", que não é senão, também, a imagem movente da expressão água sem dono retirada, por sua vez, da pintura de Pancetti.

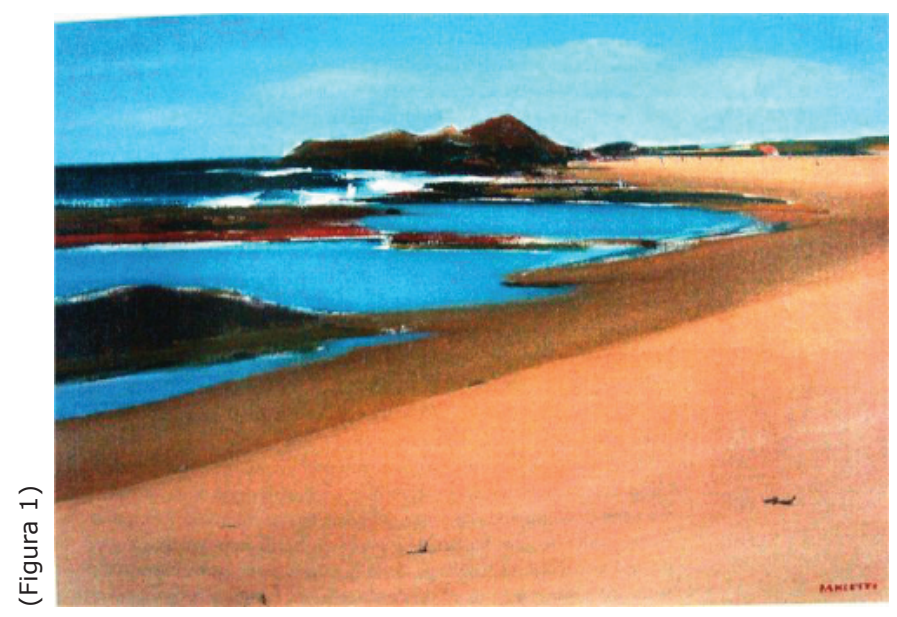

A primeira pintura se chama Ponta d'Areia (Figura 1), é de 1941. Ela apresenta uns navios atracados, a que chamamos navios-oficina, que apontam para um fascínio do olhar do marinheiro-operário Pancetti, que aparentemente não tinha um projeto de pintura - e isto foi dito por alguns que escreveram sobre a pintura de Pancetti, como José Roberto Pereira Leite ou Mauro Barata, que diziam que ele partia de um lugar melancólico ou de um quase desespero imediato para pintar -, enfim; mas o que comparece nesta tela é uma linha de sombra por dentro do movimento do mar: a surpresa daquilo que aparece pela frente, um gesto para a intuição, qualquer linha de terra ou horizonte, uma tentativa de alcançar a intimidade das águas que penetram o abismo de sua própria transparência ao "atingir o leito arenoso em que descansam", como sugere Joaquim Cardozo. Há aí, nesta primeira imagem, possivelmente, uma indicação daquilo que Joaquim Cardozo escreveu sobre O Salão do Mar $^{3}$ em um texto de 1958 publicado na revista Paratodos (Salão que foi uma iniciativa do Serviço de Documentação do Ministério da

\footnotetext{
${ }^{3}$ Esta edição do Salão do Mar contou com trabalhos de Djanira, Frank Schaefer, Ana Letícia, Fayga Ostrower, desenhos de Renina Katz e Geza Heller, gravuras de Rossini Perez, Thelma Barreiros, Ismênia Coaracy, Vera Tormenta e Darel Valença etc.
} 
Viação e Obras Públicas, em 1958); Joaquim publicou este texto um mês antes de publicar um outro especificamente sobre o trabalho de Pancetti (ainda por conta da exposição individual, no MAM do RJ, em 1955). Joaquim Cardozo diz que

Neste país de extensa costa litorânea, de mar tão vário, de cor e perspectiva aérea, que oferece matizes de cinza e alumínio nos mares do Sul e azul profundo e verde intenso, ornados de tons violáceos e amarelentos, nos horizontes marítimos do Nordeste; neste país de praias tão vestidas de vegetação; de coqueirais abertos em gesto de adeus permanente ou de bem-vinda aliança, de cajueiros derramados no chão, de gameleiras e amendoeiras, é quase indispensável que se tenha todos os anos um salão do mar; um salão de pinturas, de desenhos e gravuras que comuniquem, todos os anos, essa emoção tropical da luz e a beleza imaterial das manhãs sobre águas espessas e avultadas, pois, os nossos mares são luminosos e matinais. E que revelem, não apenas este lirismo e o que dele se denuncia ou se derrama sobre velas brancas de sal e de espuma, mas também todos os aspectos da atividade marítima nos portos ou dos objetivos dessa atividade nos estaleiros, nos armazéns, nos cais de embarque e desembarque, nos serviços, quase rituais, de atracar e desatracar navios; e ainda descubram no fundo das enseadas, das angras e baías, a melancólica poesia de velhos barcos apodrecendo, paralisados no seu naufrágio final, desfeitos, corroídos pelas maresias.

A imagem aberta de uma água que toca uma outra água, que não é senão a areia que se move e engole - numa capacidade onívora continuada - um sem número de territórios e espaços de terra, como se fosse um embaço ou uma burla de contaminação, um contato. É esta água que vem como uma reconciliação e um mover-se para encontrar-se com a outra água, de areia ou a areia, que se arma como imagem numa mistura: água / areia, a que ele chamou de águas sem dono. E isto se compõe, nesta tela, como um cenário impreciso de formas materiais animadas de uma vida, diz Joaquim Cardozo: são

os elementos de ferro erguidos no ar (que) se exprimem numa grandeza de vegetação impetuosa e enérgica, (que) se agitam no tumulto de uma fauna bizarra composta de animais monstruosos de forma e movimento, seres estranhíssimos de aspecto e comportamento tão inesperados que se poderia pensá-los saindo de uma mitologia nova.

O mar, então, para Pancetti, segundo Joaquim Cardozo, é um elemento de atração e sedução, que o faz pintar não o mar, mas a água - como remanso e também como um elemento revolto e violento, seguindo o movimento browniano (quando o que se move se move por causa do movimento das ínfimas partículas de água no chão submarino, ou seja, a forma-formante). Estas águas vêm livres e se aquietam no espaço profundo da baía, criando um valor próprio e ao mesmo tempo um valor de contorno, o que Joaquim Cardozo chama de "belas especulações do espírito humano que não deixam de ser uma maneira inteligente de o homem brincar com o infinito". E completa: 
Pintor de água, Pancetti tomou para motivo da sua arte talvez o mais legítimo suporte de sonho, ou melhor, de devaneio cotidiano, presente em todos os espíritos, mesmo os mais revestidos de utilidade imediata e de atividade prática. Da água já se disse que era o pêndulo do mundo, balança simbólica em que comparecem e se comparam a imaginação e a fantasia, relógio de um tempo sempre futuro e esperado. Suporte do sonho... José Pancetti, marinheiro de profissão, nos seus longos dias de navegação, era sobre as águas que mantinha os seus olhos, e da mobilidade delas e da sua extensão é que Ihe vinham aquele apoio interior, como um solo, um caminho para o seu devaneio, para a divagação do seu espírito nas regiões mais sutis da memória, da esperança e da saudade.

Suporte para o seu devaneio foram também as areias, que, como as águas, possuem a capacidade de se mover, e nessa mobilidade têm uma força de aderência e de sustentação como a das águas; Pancetti pintou também as areias, as areias das dunas das praias baianas, e foram elas talvez, com as suas cores de valor, ou claras de saturação, que the deram esse sentido quase místico da paisagem, e essa nota de isolamento e solidão que transparece nos seus quadros.

Há um calor nas areias de Pancetti, um sopro de vaporizações tropicais na claridade e na tranqüilidade, no equilíbrio de tudo!
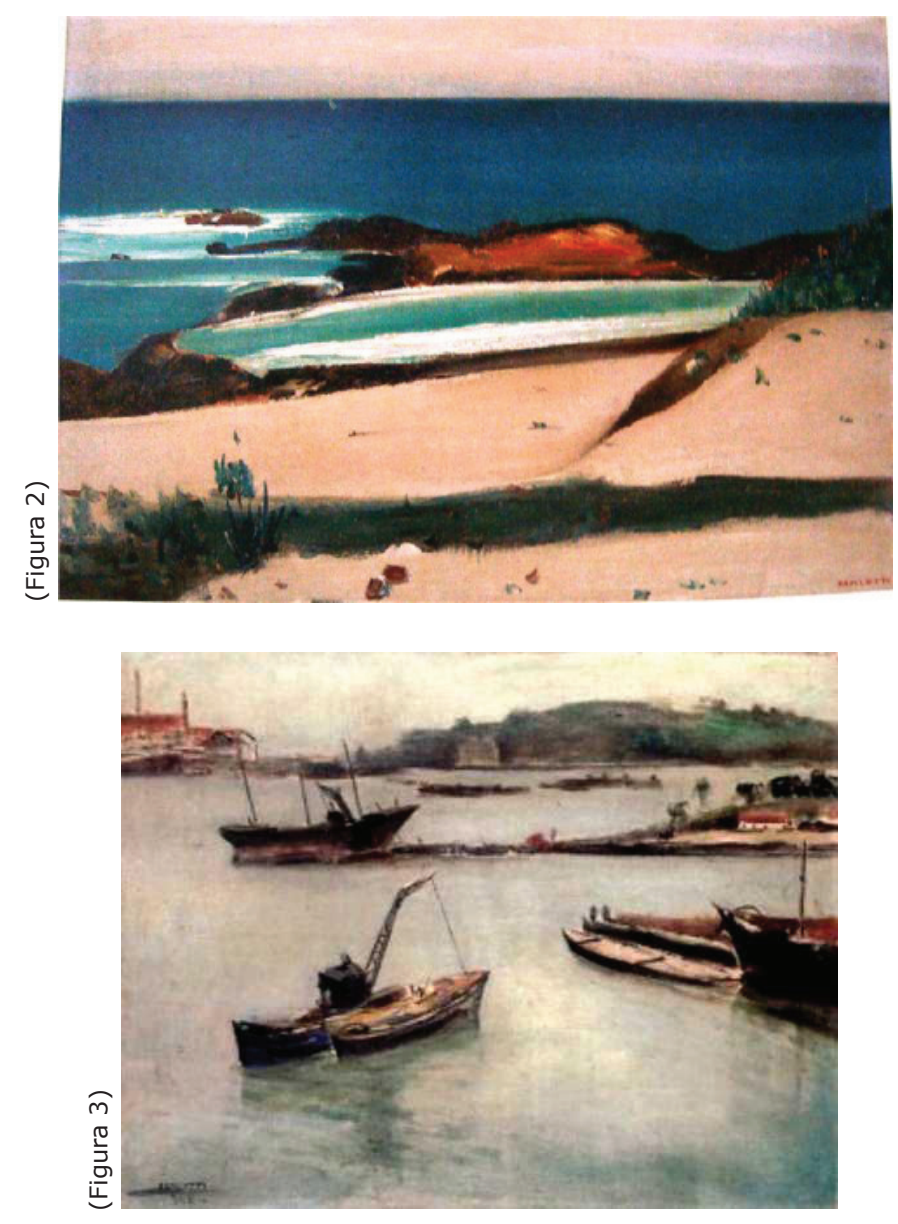

A segunda e a terceira imagens (Figuras 2 e 3), intituladas Marinha (s/d) e Marinha-Ondina (1954, que faz parte de uma série com este título), apontam para este encontro a que se refere Joaquim Cardozo, água e areia, ou água e água, com um detalhe singular na pintura de Pancetti que é o estreitamento do horizon- 
te, da linha de horizonte, ao fundo. Uma espécie de aproximação entre terra e céu que, de certa maneira, remete intuitivamente ao episódio maculado do Un Coup de Dés de Mallarmé: durante a tempestade, lembrem, o marinheiro-náufrago de Mallarmé se vê num espaço estreito; a tempestade baixa as nuvens negras do céu violentamente contra o mar que, por sua vez, sobe as suas águas ao máximo até tentar, com fúria e espasmo, tocar a linha do horizonte, tocar nesta linha o mar e o céu ao mesmo tempo. É esta a imagem que o marinheiro-náufrago vê, e assim parece se perguntar sobre a força trágica da vida ou quais as probabilidades de uma tênue linha harmônica possível, se ao lançar os dados eles possam, numa queda, fundar ali uma combinação numérica que monte alguma insuspeita harmonia para colocá-lo a salvo. Por fim, opta, numa desistência ou numa aceitação do acaso, do acidente, num acordo destituído, por deixar-se levar mar adentro, e abaixo, num gesto sob, para a morte, porque "todo pensamento emite um lance de dados". Dois pequenos exemplos do poema de Mallarmé na tradução de Augusto, Haroldo e Décio:

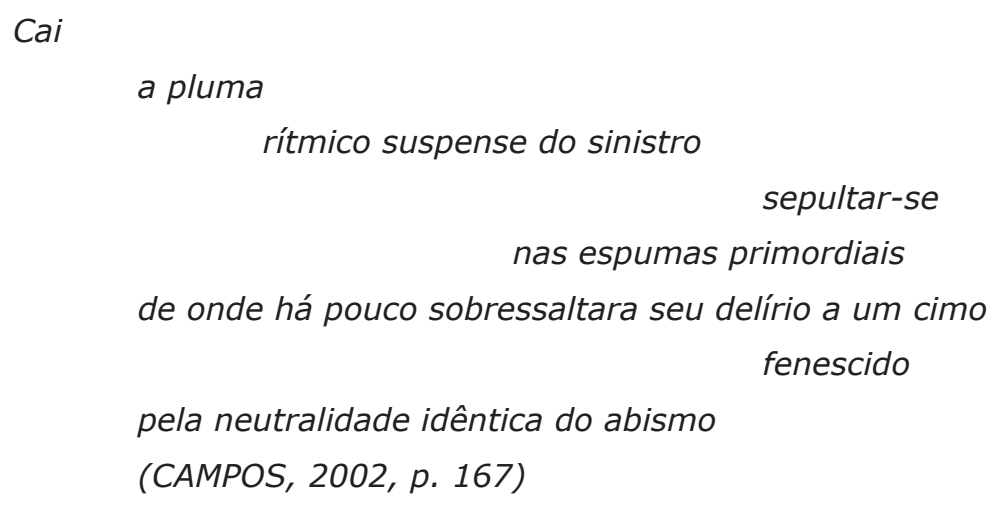

ou:

EXCETO

à altitude

TALVEZ

tão longe que um local

se funde com o além

(Idem, p. 170)

É talvez este mesmo horizonte fundido de Mallarmé que Pancetti - de outra maneira - pinta muito alto, ou seja, mais perto ainda do céu, e também (ao mesmo tempo, muito baixo) muito mais perto do mar, sem a arqueadura clássica dos marinistas com aquelas luminescências e irisações ${ }^{4}$ comoventes (esta expressão é de Joaquim Cardozo), o que arma a zona espectral, em que parece se ver mais de um horizonte por causa da sua força de variação e aderência da água à areia e vice-versa como um pêndulo do mundo. Esta linha, entre imaginação e fanta-

${ }^{4}$ Propriedade óptica apresentada por certos corpos que decompõem a luz produzindo várias cores do espectro visível. 
sia, é que toca as zonas de água, as zonas de areia, entre a praia e o mar, entre o mar e o céu. E é um pouco por causa dessa aparição do horizonte, como uma dobra matizada e em queda, que Joaquim Cardozo vai afirmar que se "um só horizonte é símbolo de fuga e de evasão, vários representam retorno, reconciliação e repouso", e que é por isso que "tudo na pintura de Pancetti é reconciliação com as paisagens do mundo, repouso na adesão e na simplicidade da sua vida". E que este empenho, para uma variação matizada do horizonte, provoca uma "ênfase para essa sua necessidade de pacificação e de retorno"; e que talvez por isso ele, marinheiro, tenha escolhido "o mar - o cenário mais dramático da paisagem - como tema central da sua arte". E esta zona armada aí, por Pancetti e por Joaquim Cardozo, pode também ser o deserto.

Não custa lembrar que para Deleuze o mar é um arquétipo de todas as estriagens do que ele chama de espaço liso, e como tal uma estriagem do deserto e uma potência de desterritorialização, um espaço nômade para cumprir o nomadismo do espaço, um espaço aberto. O que faz sentido como uma espécie de imagem sem dono, aquilo que transforma uma forma obstinada de peso imenso numa estrutura flutuante, livre, solta e que pode dançar, oscilar, tanto quanto as águas sem dono de Pancetti no princípio da forma-formante de Joaquim Cardozo. Joaquim Cardozo, aliás, aponta em Pancetti, como se apontasse a si mesmo, através do mar como um espaço nômade, para o seu valor próprio e de contorno, o do "sentido quase místico da paisagem", uma "reconciliação com as paisagens do mundo, repouso na adesão e na simplicidade da sua vida" e uma "solidariedade entre o ser e o agir, entre o ser e o continuar". Diz ele:

A pintura para Pancetti foi o seu domicílio absoluto, construído com as suas próprias mãos, de água, de areia e de horizontes, substâncias de dimensões longínquas e perdidas, mas por ele limitadas à região do seu ser e da sua alma; região da qual nunca se afastou, realizando esta coisa já hoje rara que é a solidariedade entre o ser e o agir, entre o ser e o continuar.

\section{Digressão número um}

Numa passagem de um relato de Joaquim Cardozo, um manuscrito sem data, acerca de uma sezão sem fim, que o tomou de assalto dentro de um barco, como um marinheiro distraído com as águas, entre ataques de frio e febre, deitado numa rede da Baía da Traição, ou no porão do barco - uma lancha a vela - em que viajou até Cabedelo, depois num banco do trem Paraíba-Recife, volta-se a encontrar a efígie da água sem dono numa paisagem para a forma-formante agora composta por um entorno de imagens do vento. Ventos que indicam a impossibilidade de medida do tempo, de medida da história e se perguntam qual a compreensão da vida pequena quando se opta pelo acaso, pelo acidente ou por deixar-se levar.

O ato mais radical do relato é a composição da autobiografia apagada como desvio da escritura, através da figuração do vento que comparece como a imposição de um vazio acidental e expansivo para dentro, como uma interrupção perigosa 
da passividade e do desastre. Porque o desastre pode se compor na impropriedade de um nome, na desaparição de um nome; Blanchot diz que o desastre é um tempo em que já não se pode por em jogo uma vida que se procura, nem "por deseo, ardid o violencia" (BLANCHOT, 1987, p. 41), e que "mediante ese juego, seguir manteniendo, tiempo en que calla lo negativo y a los hombres ha sucedido el infinito inquieto" (Idem, p. 41).

O jogo de Joaquim Cardozo com o vento é que há uma morte possível e, como tal, a iminência de morrer passa a ser uma fala que suplica a um infinito inquieto e a uma busca da vida através dos elementos de "sentido quase místico da paisagem", numa espécie de "reconciliação com as paisagens do mundo", numa "solidariedade entre o ser e o agir, entre o ser e o continuar". Joaquim arma um desvio da escritura para tocar num rumor as possibilidades de um real impossível, numa brincadeira com o infinito, criando uma borda, um bordejo; diz ele:

O vento era um vento contínuo, batido, meticuloso; jogava, oscilava, dançava sobre as águas; se erguia, aprumava-se, subia; e de novo, do sul, nos trazia uma vibração de asas diluídas, desfeitas, decompostas, um ritmo pesado, seguro, constante; com ritmos, ora permanentemente do sul, ora ligeiramente variando para leste, para o horizonte do mar; mas sempre contra, contra a nossa vela aberta naquela noite incompleta, naquela noite que, dentro em pouco, iria concluir-se. Para avançarmos na direção de Cabedelo, precisávamos bordejar, éramos forçados a bordejar, o que iria prolongar a viagem em muitas horas. E os tropeços que iria dar esse bordejo em ziguezague de linhas retas, de linhas líquidas e vacilantes? A que horas avistaríamos Cabedelo? Bordejamos. O Barco navegava penso de um lado.

E num desafio de enfrentamento do desconhecido, prossegue:

Penetrávamos com a vela inclinada, até um ponto muito avançado, no mar, como procurando contornar o vento, ou descobrir dentro dele uma passagem; depois cambando e molhando a vela, voltamos até bem perto da praia, num ziguezague lento e monótono. Depois, puxando de novo as escotas da vela latina da lancha e cambando-a, dirigimos de novo o barco para o longínquo horizonte marítimo. Era um bordo difícil, de oscilações muito longas, um movimento como de negaças diante do Sulão que continuava a soprar sem cessar. A assobiar e a zumbir num assobio agudo e melancólico, um uivo como se viesse de uma matilha de lobos perdidos e famintos naquele mar generoso. Fomos assim bordejando, procurando vencer o forte vento que não nos dava trégua, que continuamente soprava naquele fim de noite, naquela vindoura madrugada; o barco ia adernado de um lado; por isso, ficávamos sentados do outro lado como contrapeso; junto a nós estava o taiassu - a âncora da lancha - para manter melhor o equilíbrio, mas o vento forte continuava a adernar o barco.

Depois, numa espera para uma fresta, um neutro da linguagem no vento, seu negativo, sua diferença oculta, seu fragmento de horizonte entre o mar e o céu, entre o vento ali e um outro vento que vem: 
Com aquele bordejo contínuo comecei a enjoar de maneira intensa, mas o bordo continuava. A lancha velejava sempre ao longo da muralha do vento, à procura de uma fresta, de uma fenda, na ventania desesperada, de uma abertura para poder passar e, do outro lado, encontrar outro vento mais amigo, suave e leal.

O relato encontra a forma-formante do vento como um informe da escritura, uma desconfiança, uma falsificação da aparência da própria morte, uma água sem dono: uma água que vem violenta e encontra o seu remanso na areia e revolve a areia submarina também com violência para depois remansar na água e segue, continuamente, este movimento de bordejo, águas sem dono: "escribir para que lo negativo y lo neutro, en su diferencia siempre oculta, en la proximidad más peligrosa, se acuerden mutuamente de su própria especificidad" (BLANCHOT, 1987, p. 39):

Agora, de volta, viajamos com vento contrário, o vento Sulão, que soprava do sul, do fundo escuro da noite, de um longe sul de um horizonte que se perdia entre nuvens espessas; um vento que vinha, lambendo a superfície das águas, erguendo as ondas da maré baixa, impulsionando as nuvens escuras e fragmentadas.

O vento era um vento contínuo, batido, meticuloso; jogava, oscilava, dançava sobre as águas; se erguia, aprumava-se, subia; e de novo, do sul, nos trazia uma vibração de asas diluídas, desfeitas, decompostas, um ritmo pesado, seguro, constante; com ritmos, ora permanentemente do sul, ora ligeiramente variando para leste, para o horizonte do mar; mas sempre contra, contra a nossa vela aberta naquela noite incompleta, naquela noite que, dentro em pouco, iria concluir-se.

Para avançarmos na direção de Cabedelo, precisávamos bordejar, éramos forçados a bordejar, o que iria prolongar a viagem em muitas horas. E os tropeços que iria dar esse bordejo em ziguezague de linhas retas, de linhas líquidas e vacilantes? A que horas avistaríamos Cabedelo? Bordejamos.

O Barco navegava penso de um lado.

Bordejamos, assim, ao longo de toda a costa da Paraíba: desde a Baía da Traição até o porto de Cabedelo: penetrávamos com a vela inclinada, até um ponto muito avançado, no mar, como procurando contornar o vento, ou descobrir dentro dele uma passagem; depois cambando e molhando a vela, voltamos até bem perto da praia, num ziguezague lento e monótono. Depois, puxando de novo as escotas da vela latina da lancha e cambando-a, dirigimos de novo o barco para o longínquo horizonte marítimo. Era um bordo difícil, de oscilações muito longas, um movimento como de negaças diante do Sulão que continuava a soprar sem cessar. A assobiar e a zumbir num assobio agudo e melancólico, um uivo como se viesse de uma matilha de lobos perdidos e famintos naquele mar generoso. Fomos assim bordejando, procurando vencer o forte vento que não nos dava trégua, que continuamente soprava naquele fim de noite, naquela vindoura madrugada; o barco ia adernado de um lado; por isso, ficávamos sentados do outro lado como contrapeso; junto a nós estava o taiassu - a âncora da lancha - para manter melhor o equilíbrio, mas o vento forte continuava a adernar o barco. 


\section{(...)}

Com aquele bordejo contínuo comecei a enjoar de maneira intensa, mas o bordo continuava. A lancha velejava sempre ao longo da muralha do vento, à procura de uma fresta, de uma fenda, na ventania desesperada, de uma abertura para poder passar e, do outro lado, encontrar outro vento mais amigo, suave e leal.

(...)

Tudo que era da Baía Formosa deixei, deixei os barcos a vela, o vento Sulão, a aldeia de Marcação, as belas praias da Paraíba; somente as sezões me acompanharam, amorosamente me acompanharam, até Pernambuco, até o Recife, até a Rua da Estância, onde eu morava.

(CARDOZO: manuscrito, s.d.)

\section{Digressão número dois}

A questão não é apenas o quanto o deserto se fulgura numa dimensão do território, do ser, ou do quanto não é uma imagem, mas também e principalmente porque solicita um prolongamento do que não é uma imagem, do que não é um sentido para o sentido, mas sim uma ambivalência no espaço da forma, como informe, como forma-formante, como uma contingência que interfere radicalmente nas brechas de uma geografia do ser, como as linhas provocadas pelos trabalhos de Pancetti. O deserto, se é um espaço aberto para as oscilações da forma, é também um espaço aberto para a aventura, uma imposição de uma presença na ausência do sentido para que através de uma penumbra poética, como uma política para o confim e para o comum, haja também uma presença na ausência do ser-no-mundo.

Deleuze diz que no deserto não se enxerga de longe, que não se enxerga o deserto de longe, que nunca se está diante do deserto e, tampouco, se pode estar dentro dele. E lembra Cézanne, que falava da necessidade de perder-se sem referência: para pintar um campo de trigo, ficar muito próximo dele a ponto de não vê-lo mais. Perder-se sem referência é mover-se num espaço liso que por sua vez se move e faz mover um espaço estriado, o que detém a medida das coisas no mundo. Deleuze diz ainda que se pode recuar em relação às coisas, mas que não é um bom pintor aquele que recua do quadro que está pintando: "Um quadro é feito de perto, mesmo que seja visto de longe" (DELEUZE, 1997, p. 204) Assim como para o escritor, acrescenta, é possível escrever com uma memória curta, mas se presume que o leitor seja dotado de uma memória longa. Conclui dizendo então que a maneira de enxergar o deserto é "está-se nele" (Idem, p. 204), e que estar nele é então uma incorporação, não como organismo ou organização, mas como intensidade; porque o deserto é um espaço nômade, sem tempo, sem memória, sem peso, sem leveza, háptico (que seria uma sobreposição do sentido, entre o tátil e o ótico, quando até mesmo o olho pode não ser apenas ótico), nem começo nem termo, aquilo que se desenha numa linha também nômade, "que nada delimita, que já não cerca contorno algum, que já não vai de um ponto a outro, mas que passa entre os pontos, que não pára de declinar da horizontal e da vertical, de desviar da diagonal mudando constantemente de direção" (Ibid., p. 210). 
Platão, bem antes, comenta no Timeu que os conceitos de leve e pesado devem ser estudados juntamente com a natureza e do que se denomina, também como conceito, de em cima e embaixo. Ele explica que é um erro manifesto acreditar que há, por natureza, uma divisão do universo a partir dessas duas regiões opostas: "a de baixo, para onde cai tudo o que tem massa corpórea, e a de cima, para onde nada se dirige a não ser com relutância" (PLATÃO, 2001, p. 107). Para ele o céu é esférico, e assim todos os pontos extremos do universo teriam uma mesma distância para um suposto centro que, por sua vez, manteria também uma distância e uma mesma medida com todas essas extremidades. O cosmo, para Platão, como uma imagem móvel da eternidade, está constituído assim numa dimensão de extremos, e qualquer tentativa de mensurá-lo se apresenta como descabida ou, como ele diz, esta tentativa parte de uma expressão sempre inadequada: "Não se pode dizer que esteja no alto ou embaixo; acha-se, simplesmente, no centro, enquanto a circunferência, sem dúvida, não poderá ser central, nada havendo que permita distinguir umas partes das outras, com referência ao centro, que não se encontre também nas partes que Ihes sejam opostas." (Idem, p. 108) A partir disso Platão pressupõe um espaço liso e um espaço rugoso, o primeiro que seria proveniente da igualdade das partes com a densidade, e o segundo que seria resultante da combinação da dureza com a desigualdade. Isto tem a ver com a geodésica do mundo da qual o tempo faz parte, como a geodésica proposta por Joaquim Cardozo a partir da pintura de Pancetti, que é uma linha que cobre uma superfície, uma curva cuja normal principal coincide, em cada ponto, com a normal a essa mesma superfície.

A linha, pois, a que Deleuze se refere como sustentação do espaço liso tem a ver com o espaço liso de Platão, porque não é inexpressiva, mas proveniente de uma relação igual das partes com a densidade, e que por isso pode impor uma abertura cósmica do espaço nesta natureza que nos toca, porque é uma linha que pode ser considerada mutante, e como tal, é uma linha "sem fora nem dentro, sem forma nem fundo, sem começo nem fim, tão viva quanto uma variação contínua, é verdadeiramente uma linha abstrata, e descreve um espaço liso" (DELEUZE, 1997, p. 210). Deleuze diz que o espaço liso não pára de ser traduzido e misturado ao espaço estriado, que por sua vez é o tempo inteiro revertido a um espaço liso, que é por onde o deserto se propaga como uma casa nômade, espaço exterior, aberto, onde o corpo se move. O espaço liso é um nomos, uma conformação aberta do espaço do dentro ao espaço do fora. É como uma vestimenta que se amolda ao corpo para que ele se mova no aberto do mundo, e não o corpo que se amolda à vestimenta para fixar-se. É como numa tapeçaria, numa colcha de retalhos que demonstra claramente que "o liso não quer dizer homogêneo; ao contrário, é um espaço amorfo, informal" (Idem, p. 182).

\section{Bibliografia:}

CARDOZO, Joaquim. Salão do mar. Para Todos: quinzenário da cultura brasileira, 
Rio de Janeiro, São Paulo, v. 2, n. 42-43, p. 9, fev. 1958.

O Pintor Pancetti. Para Todos: quinzenário da cultura brasileira, Rio de Janeiro, São Paulo, v. 2, n. 44, p. 9, mar. 1958.

BARATA, Mauro, LEITE, José Roberto Teixeira e PERLINGEIRO, Max. José Pancetti (1902-1958) Marinheiro, Pintor e Poeta. São Paulo: Pinakotheke, 2003.

BLANCHOT, Maurice. La escritura del desastre. Monte Ávila: Caracas, 1990.

DELEUZE, Gilles. Mil Platôs - Capitalismo e Esquizofrenia - 5. Trad. Peter Pál Pelbart e Janice Caiafa. São Paulo: Ed. 34, 1997.

PLATÃO. Timeu - Crítias - O Segundo Alcebíades - Hípias Menor. Trad. Carlos Alberto Nunes. Belém: EDUFPA, 2001.

Title:

Joaquim Cardozo and Pancetti, waters without owner

\section{Abstract:}

This work starts with the Joaquim Cardozo's reading of the image of water in the sailor Pancetti's painting as an element of "almost mystic sense of the landscape", a kind of "reconciliation with the world's landscapes", a "solidarity between being and acting, between being and continuing", all that in a brownian movement of shades. Cardozo calls this image waters without owner. The question of this work is how he re-elaborates his concept of forming-form from the Pancetti's painting.

\section{Keywords:}

Forming-form; landscape; painting; Joaquim Cardozo; Pancetti 